\author{
Kétsia Rayssa Henriques \\ Ferreira $1 *$ \\ Josiclei de Castro Moraes ${ }^{2}$ \\ Clarina Louis Silva Meira ${ }^{1}$ \\ Lucas Lacerda de Souza ${ }^{3}$ \\ Nicolau Conte Neto ${ }^{4}$ \\ Thiago Brito Xavier ${ }^{4}$
}

\section{Treatment of oroantral fistula: case report}

\begin{abstract}
:
The oroantral fistula is a pathological communication between the oral cavity and the maxillary sinus that is covered with epithelial tissue from both sites. It may be caused by dental infections, surgical iatrogenesis, radiotherapy or trauma. To avoid contamination of the maxillary antrum, this connection must be closed. Several tissue flaps may be used for this. The aim of this paper is to present a case of oroantral fistula treatment in the posterior region of the left maxilla using a vestibular sliding strip flap with palatal interposition. A 54-year-old female patient was presented with an oroantral fistula confirmed by the Valsalva maneuver and radiographic examination. The patient was previously exposed to antimicrobial treatment in order to solve the acute infectious disease, which was accompanied by surgical closure. Dehiscence and drainage via fistula in the postoperative period motivated the performance of a second surgical procedure using a sliding vestibular flap with palatal interposition. It is concluded that infection prevention is important for the effectiveness of treatment, as well as patient's cooperation in the postoperative period.
\end{abstract}

Keywords: Oral surgery; operative surgical procedures, maxillary sinus

\footnotetext{
${ }^{1}$ Federal University of Pará (UFPA), Dentistry Student, Faculty of Dentistry - Belém - Pará - Brasil.

${ }^{2}$ Federal University of Pará, Resident in Oral and Maxillofacial Surgery and Traumatology, João de Barros Barreto University Hospital Belém - Pará - Brasil.

${ }^{3}$ Federal University of Pará, Resident in Integrated Clinic, João de Barros Barreto University Hospital - Belém - Pará - Brasil. ${ }^{4}$ Federal University of Pará, Professor at the Residency of Oral and Maxillofacial Surgery and Traumatology, João de Barros Barreto University Hospital - Belém - Pará - Brasil.
}

Correspondence to: Kétsia Rayssa Henriques Ferreira. E-mail: ketsiar9@gmail.com

Article received on March 7, 2021. Article accepted on July 16, 2021.

DOI: 10.5935/2525-5711.20210016 


\section{INTRODUCTION}

The oroantral fistula is a pathological communication between the oral cavity and the maxillary sinus with several causes, including trauma, dental infection, osteomyelitis, radiation therapy and extraction of upper molars. This last cause is the most frequently seen due to the anatomical position of the apexes root with the maxillary sinus floor ${ }^{1,2,3}$. This communication is more common between 30 and 60 years old. It is more prevalent in men than in women ${ }^{4}$, due to the greater number of extractions in this group of patients ${ }^{5}$.

The diagnosis of this pathological condition can be performed by Valsalva maneuver, which consists of a moderate forceful attempted exhalation against the maxillary sinus. It is made by pressing the nostrils together to occlude the nose and telling the patient to breath gently through the nose while the surgeon observes whether there is air passage from the maxillary sinus to the oral cavity ${ }^{6,7,8}$.

Radiographic exams can be used as diagnostic complement. The panoramic radiography may be useful to provide a screening in order to identify aspects evidencing the presence of fistula, such as discontinuity of the sinus floor, increase in the radiopacity, besides to allow a comparison between the maxillary sinuses ${ }^{4}$. In addition, radiography with Waters view provides a more accurate information regarding the extension and limits of the communication ${ }^{6,9,7}$.

The treatment of closing communication must be managed to prevent food and saliva contamination, which can lead to bacterial infection, impaired healing, and chronic sinusitis ${ }^{7,10}$. However, its size and the occurrence of active infection need to be previously determined, since the effectiveness of treatment depends on the sinus health ${ }^{6,2,8}$. Several flaps are reported in literature to close the oroantral fistula and all of them present both advantages and limitations. However, the buccal and palatine flaps, as well as Bichat buccal fat pad are the most commonly described ${ }^{11,12,13,14}$.

Based on the need to understand the treatment of the oroantral fistula and its possible consequences, the aim of this study is to report a case report of a 54-yearold female patient who was presented with a oroantral fistula in the posterior region of the left maxilla and was treated with a vestibular sliding strip flap with palatal interposition.

\section{CASE REPORT}

A 54-year-old female patient was referred to the Oral Pathology and Oral and Maxillofacial Surgery Departments of the University Hospital João de Barros Barreto for the treatment of a fistula presented four years after extraction of the left maxillary second molar. The patient reported a previous history of two attempts to close the oroantral communication. However, both were unsuccessful and the last was performed two months ago, leading to the development of a recurrent sinusitis.

Under clinical examination, it was noted a fistula linking the oral cavity with maxillary sinus in the region of the left upper maxilla, in the same site of the left maxillary second molar (Figure 1A). The Valsalva maneuver was performed to confirm the diagnosis, and the radiographic examination revealed a bone defect measuring $19 \mathrm{~mm}$ in the mesio-distal and $12 \mathrm{~mm}$ in the vestibulo-lingual directions (Figure $1 \mathrm{~B}$ ).

Preoperative antimicrobial therapy was started with amoxicillin $500 \mathrm{mg}$ and clavulanic acid $125 \mathrm{mg}$ for

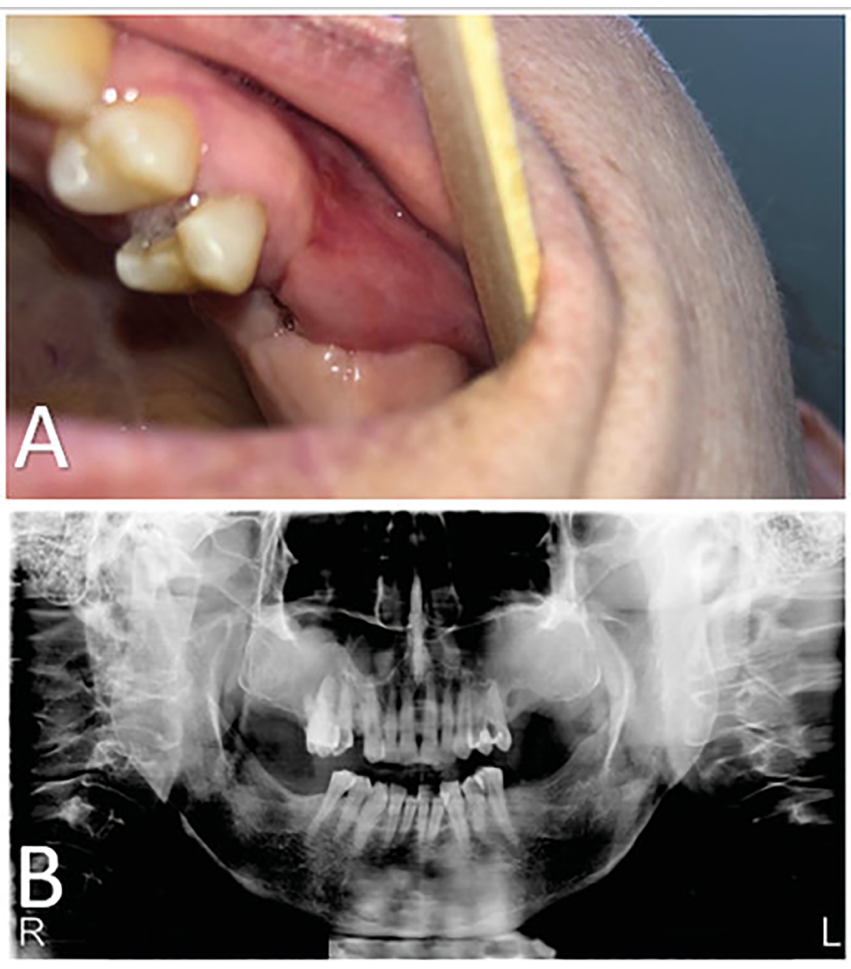

Figure 1. Initial clinical aspect and panoramic radiography. A) The patient waspresented with afistula linking the oral cavity with maxillary sinus in the region of the leftupper maxilla, in the same site of the left maxillary second molar. B)Radiographic aspect showing opacification ofthe maxillary sinus on the left, and bone defect measuring $19 \mathrm{~mm}$ in the mesio-distaldirection and $12 \mathrm{~mm}$ in the vestibulo-lingual direction. 
07 days to control the acute infectious process. After remission of signs and symptoms, surgery was scheduled using the vestibular advancement flap and Bichat buccal fat pad.

The first surgical procedure was performed under local anesthesia to cover the exposed bone defect. Postoperatively, amoxicillin $500 \mathrm{mg}$ and clavulanic acid 125 $\mathrm{mg}$ for 07 days was maintained, and was supplemented with nimesulide $100 \mathrm{mg}$ and dipyrone $1 \mathrm{~g}$ for inflammatory and pain control. The patient received postoperative instruction, and was advised not to smoke, not to blow her nose, not to sneeze with her mouth closed, or to perform any operation that favored the differential in pressure between the oral cavity and the sinus. There was good healing at the site during the 7-day postoperative period, although a slight dehiscence in the suture region in the attached gingiva, but with no sign of buccosinusal communication. Due to a coughing condition, the patient developed a dehiscence of the injury 14 days after surgery. Therefore, amoxicillin $500 \mathrm{mg}$ and clavulanic acid $125 \mathrm{mg}$ were prescribed for more 7 days and general care was again instructed.

A second surgery was performed, where a sliding vestibular flip flap was made and an envelope was created in the palatal region to cover the flap margins (Figure 2A-B). In the postoperative period, the same drugs were maintained for pain control and infection prevention, as well as being informed about the general and specific care inherent to the procedure realized. The patient

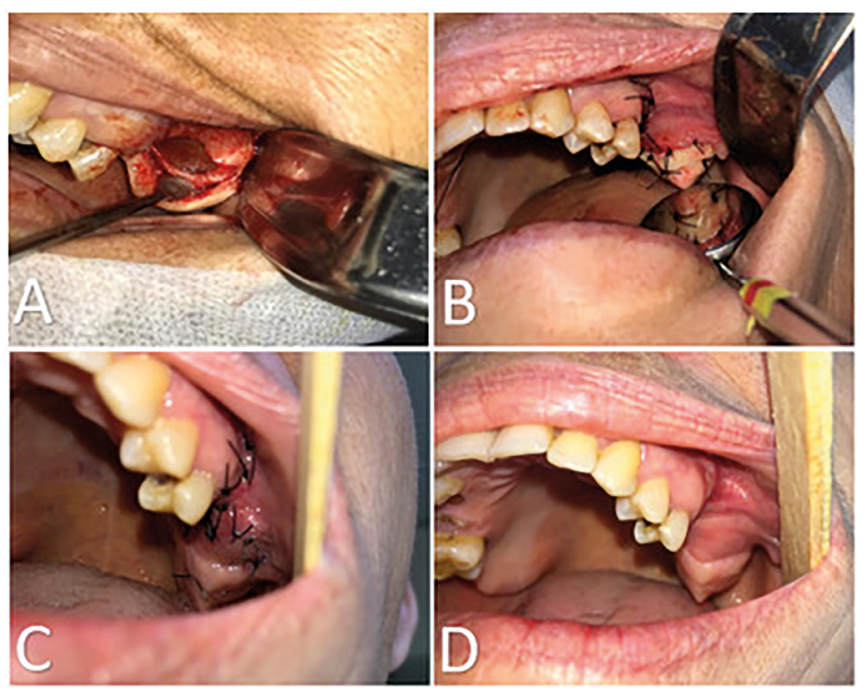

Figure 2. Transusrgical procedure andfollow-up. A) Exposureof the maxillary sinus. B) Immediate appearance of the postoperative periodshowing the sliding vestibular flip flap with palatal interposition. C)Appearance of the flap 7 days after surgery, showing no dehiscence orinfectious process. D) A 14-day postoperative period showing the healingachieved. returned after 7 days to remove the suture and presence of infectious process or dehiscence of the affected region was not noted (Figure $2 \mathrm{C}$ ). In the 14-day postoperative period, the patient returned with a clearly achieved healing process (Figure 2D). Actually, the patient is in a 14-month follow-up period with no signs of recurrence.

\section{DISCUSSION}

Previous literature have described certain conditions associated with predisposition to the occurrence of oroantral communication after tooth extractions, such as pneumatized maxillary sinus with little alveolar bone remaining and presence of divergent dental roots ${ }^{6,4,15}$. The extraction of molars and premolars is often associated with oroantral fistula ${ }^{1,16}$. According to Galli et al. ${ }^{11}$ and Juno et al. ${ }^{2}$, the second premolars and first molars are more linked to this condition, which can be confirmed in the present case report. Madeira ${ }^{17}$ states that, anatomically, the root apexes of the second molars are closer to the maxillary sinus and, indeed, contribute to the oroantral communication.

The radiographic aspects correspond to a radiolucent area and be delineated in all peripheral areas by a well demarcated layer of cortical bone $e^{6,9}$. In the present case, the opacification and discontinuity of the sinus floor were noted, corroborating with previous literature. As mentioned by Borgonovo et al. ${ }^{18}$, these aspects are suggestive of the presence of communication associated with sinus infection ${ }^{19,15}$.

The passage of air and fluids between the nose and the mouth are clinical findings of the presence of oroantral fistula. According to Kwon et al. ${ }^{8}$, the patient can report symptoms such as bad taste and smell, pain in the affected region and reflux of food from the nose to the oral cavity. Sinusitis caused by sinus infection was also exposed by Khandelwal and Hajira ${ }^{1}$. Other authors mentioned unilateral nasal obstruction and nocturnal cough due to drainage of exudate into the pharynx ${ }^{9,20}$.

According to Hupp et al. ${ }^{6}$, antibiotics that are effective against odontogenic infections, including penicillin, clavulanic acid, clindamycin and metronidazole, are also effective against odontogenic sinusitis ${ }^{7,8}$.

The literature reports on the principles for making vestibular advancement flaps, including the elevation of a wide base flap with adequate width to cover the defect $^{1,6,19}$. Some authors argue that their margins should be positioned on the healthy bone instead of being placed directly on the communication area ${ }^{6}$ and that it is free of any tension decreasing the possibility of necrosis ${ }^{9,13,18}$. 
The Bichat buccal fat pad is recommended as the flap when the communication is greater or equal to 3 $\mathrm{mm}^{4}$, consistent with the present case which showed satisfactory result with the technique. The advantages of this flap include a rich vascularization that favors the successful use of the adipose body as a pedicled flap, it is closed to the site of surgical correction, make a faster surgical procedure and low-cost showing good success rates ${ }^{14,16,21,22,29,24}$. Colella et al. ${ }^{25}$ argues that it is not necessary to cover the flap with epithelial tissue because a granulation tissue is formed which is replaced by paraquearatinized stratified squamous epithelium. However, studies show that the disadvantages include the possibility of trismus in the postoperative period, the fact that it can only be used once and does not offer rigid

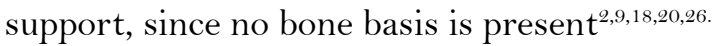

The vestibular flap is defended by some authors as ideal for closing small defects, when the alveolar ridge is very reabsorbed and the location of the fistula tend to be presented in mesial region ${ }^{5,27}$. Borgonovo et al. ${ }^{18}$ declares that in larger defects, this flap can be combined with the palatal flap because it is an easily distended tissue, and it presents a simple surgical technique, also demonstrating positive results ${ }^{4,20}$. However, it causes loss of the bone remaining, which makes difficult the prosthetic rehabilitation in the affected patients ${ }^{8,15}$.

Patients must have attention in the postoperative process since the complete healing depends on patient's care. Parvini et al. ${ }^{5}$ reported the need for oral hygiene, a diet with light foods and, mainly, avoid blowing and smoking ${ }^{11,19}$. In the present clinical report, it was found that the patient's non-adherence to personal care increased dehiscence in the first postoperative period, which favored the first procedure failure and motivated the second surgery.

According to Hupp et al. ${ }^{6}$, the best treatment for the oroantral fistula is to prevent the occurrence of this pathology. It is necessary a good treatment plan, detailed evaluation of the radiographs to check the condition of the sinus and if the tooth to be extracted presents any condition which may cause oroantral communication. One way to decrease the possibility of this condition occurring is the section of the roots ${ }^{4}$.

\section{CONCLUSION}

The oroantral fistula is a pathological communication between the oral cavity and the maxillary sinus. There are several techniques well-documented in the literature for the treatment. In this clinical case, the use of sliding vestibular flip flap with palatal interposition proved to be viable for the correction of large defects. The infection control, through patient's collaboration in postoperative, it is essential to avoid new procedures.

\section{REFERENCES}

1. Khandelwal P, Hajira N. Management of oroantral communication and fistula: various surgical options. World J Plast Surg. 2017;6(1):3-8. DOI: https://doi.org/10.11604/ pamj.2019.34.69.19959

2. Araújo Júnior JL, Araújo AM,

Olegário RB, Magalhães MCF, Paiva M, Cairiri T, et al. Use of body adiposo body in oroantral communication. Rev Cir Traumatol Buco-maxilo-fac. 2019 Jul/sep;19(3):30-4.

3. Marcantonio C, Palmieri M, Gorga DV, Pereira MO, Nícoli LG, Jorge WA. Use of a palatal pedicle flap for closure of an oroantral fistula. Rev Gaúch Odontol. 2015 Oct/ Dec;63(4):496-501. DOI: https://doi.org/10.1590/1981863720150003000202954

4. Anjos FNFG, Melo MCG, Leite IF, Melo DP, Lucas LA, Macedo LFC, et al. Surgical approach to buccal-sinus fistula closure by vestibular flap technique: case report. Electr J Collect Health. 2019;(29):e1557. DOI: https://doi.org/10.25248/reas. e1557.2019

5. Parvini P, Obreja K, Sader R, Becker J, Schwarz F, Salti L. Surgical options in oroantral fistula management: a narrative review. Int J Implant Dentist. 2018 Dec;4(1):40. DOI: https:// doi.org/10.1186/s40729-018-0152-4

6. Ellis E, Hupp JR, Tucker MR. Contemporary oral and maxillofacial surgery. 6a ed. Rio de Janeiro: Elsevier; 2015.

7. Parise G, Tassara L. Medical and surgical treatment of oroantral communications: a literature review. Perspectiva Erechim. 2016 Mar;40(149):153-62.

8. Kwon MS, Lee BS, Choi BJ, Lee JW, Ohe JY, Jung JH, et al. Closure of oroantral fistula: a review of local flap techniques. J Korean Assoc Oral Maxillofac Surg. 2020;46(1):e1143281. DOI: https://doi.org/10.5125/jkaoms.2020.46.1.58

9. Farias JG, Cancio AV, Barros LF. Closure of oroantral fistula with pedicled buccal fat pad - convention technique $\mathrm{x}$ technique of the tunnel - cases report. Rev Cir Traumatol Bucomaxilo-fac. 2015;15(3):25-30.

10. Ahn SK, Wee SY. Oroantral fistula after a zygomaticomaxillary complex fracture. Arch Craniofac Surg. 2019 Jun;20(3):212-6. DOI: https://doi.org/10.7181/acfs.2019.00108

11. Galli M, De Soccio G, Cialente F, Candelori F, Federici FR, Ralli $\mathrm{M}$, et al. Chronic maxillary sinusitis of dental origin and oroantral fistula: The results of combined surgical approach in an Italian university hospital. Bosn J Basic Med Sci. 2020;20(4):524-30. DOI: https://doi.org/10.17305/ bjbms.2020.4748

12. Lopes PHS, Sampaio DO, Menezes BSS, Nascimento DF, Torres BCA. Combined palatal flap and titanium mesh for oroantral fistula closure. Ann Maxillofac Surg. 2015 Jan/Jun;5(1):8992. DOI: https://doi.org/10.4103/2231-0746.161090

13. Meirelles RC, Neves Pinto RM. Oroantral fistula and genial mucous flap: review of 25 cases. Braz J Otorhinolaryngol. 2008 Fev;74(1):85-90. DOI: https://doi.org/10.1590/S003472992008000100014 
14. Sharma SP. Three-layered closure of persistent oroantral fistula using chin graft, buccal fat pad, and buccal advancement flap: a case report with review of literature. Case Rep Dent. 2019;2019:8450749. DOI: https://doi. org/10.1155/2019/8450749

15. Calvet MVB, Castro BRA, Agostinho CNLF, Bastos EG. Closing bucoantral communication with Bichat adipose ball: literature review and case report. Rev Ciênc Saúde. 2014 Jul/Dez;16(2):106-11.

16. Kim MK, Han W, Kim SG. The use of the buccal fat pad flap for oral reconstruction. Maxillofac Plast Reconstr Surg. 2017 Feb;39:5. DOI: https://doi.org/10.1186/s40902-017-0105-5

17. Madeira MC. Anatomy of the face: functional anatomical bases for the dental practice. $8^{\underline{a}}$ ed. São Paulo: Sarvier; 2013.

18. Borgonovo AE, Berardinelli FV, Favale M, Maiorana C. Surgical options in oroantral fistula treatment. Open Dent J. 2012;6(1):94-8. DOI: https://doi.org/10.2174/1874210601206010094

19. Ferreira GZ, Gai T, Cerqueira GF, Daniel Filho AN, Iwaki L Farah GJ. Treatment of oroantral fistula using the buccal fat pad pedicullate flap technique: case report. Arq Odontol. $2011 \mathrm{Jul} / \mathrm{Sep}$; 7 (3):162-9.

20. Dergin G, Emes Y, Delilbasi C, Gurler G. Management of the oroantral fistula. A textbook of advanced oral and maxillofacial surgery. London: IntechOpen; 2016. DOI: https://doi.org/10.5772/63403

21. Yang S, Jee YJ, Ryu DM. Reconstruction of large oroantral defects using a pedicled buccal fat pad. Maxillofac Plast Reconstr Surg. 2018 Apr;40:7. DOI: https://doi.org/10.1186/s40902-018-0144-6
22. Alonso-Gonzalez R, Penarrocha-Diago MA, Penarrocha-Oltra D, Aloy-Prosper A, Camacho-Alonso F, Penarrocha-Diago M. Closure of oroantral communications with Bichat's buccal fat pad. Level of patient satisfaction. J Clin Exp Dent. 2015;7(1):e28-33. DOI: https://doi.org/10.4317/jced.51730

23. Hernando J, Gallego L, Junquera L, Villarreal P. Oroantral communications. A retrospective analysis. Med Oral Patol Oral Cir Bucal. 2010 May;15(3)e499-e503. DOI: https://doi. org/10.4317/medoral.15.e499

24. Gheisari R, Zadeh HH, Tavanafar S. Oro-antral fistula repair with different surgical methods: a retrospective analysis of 147 cases. J Dent. 2019 Jun;20(2):107-12. DOI: https://doi. org/10.30476/DENTJODS.2019.44920

25. Colella G, Tartaro G, Giudice A. The buccal fat pad in oral reconstruction. Br J Plast Surg. 2004 Jun;57(4):326-9. DOI: https://doi.org/10.1016/j.bjps.2004.02.005

26. Amaral MF, Guerra LAP, Gerbi MM, Melo AR, Gondim DGA, Medeiros Junior R, et al. Oroantral fistulas closure using Bichat's fat pad. Rev Gaúch Odontol. 2014 Oct/ Dec;62(4):437-42. DOI: http://dx.doi.org/10.1590/19818637201400040000132219

27. Krishanappa SKK, Eachempati P, Nagraj SK, Shetty NY, Moe $\mathrm{S}$, Aggarwal H, et al. Interventions for treating oro-antral communications and fistulae due to dental procedures. Cochrane Database Syst Rev. 2018 May;(5):CD011784. DOI: https://doi. org/10.1002/14651858.CD011784.pub3 